\title{
A rare, life-threatening effort angina and anomalous origin of the left circumflex coronary artery: $\mathrm{CT}$ and SPECT findings
}

\author{
Gian Piero Carboni, ${ }^{1}$ Pietro Sedati ${ }^{2}$
}

${ }^{1}$ Department of Nuclear Cardiology, Università Campus Bio-Medico, Rome, Italy ${ }^{2}$ Department of Radiology, Università Campus Bio-Medico, Rome, Italy

\section{Correspondence to} Professor Gian Piero Carboni, g.carboni@unicampus.it
To cite: Carboni GP Sedati P. BMJ Case Rep Published online: [please include Day Month Year] doi:10.1136/bcr-2013009005

\section{DESCRIPTION}

In July 2012, a 63-year-old man presented with effort angina occurring in a predictable fashion. $\mathrm{He}$ worked as a porter and when carrying heavy loads, angina with palpitations and feeling loss of consciousness, suggested prodromal symptoms of syncope owing to arrhythmia. Stress/rest thallium-201 singlephoton emission cardiac tomography (SPECT) revealed inferior and septal wall reversible defects (ischaemia) without ST-depression at peak during a bicycle maximal exercise test. Cardiac CT documented an anomalous origin of the left circumflex coronary artery (ACXCA) arising from the right sinus of Valsalva with an extramural course between the aorta and the left atrium (figure 1). ${ }^{1}$ The angina aetiology was mainly caused by the transient coronary flow reduction elicited by the systolic compression of the ACXCA that is produced by the aorta and the left atrium at peak exercise. In addition, the finding of hypoplastic right coronary artery (RCA) and myocardial bridge over the first diagonal branch (D1) contribute to the coronary reserve worsening during stress exercise (figure 2). ${ }^{2}$ The patient was treated with slow-release metoprolol, $200 \mathrm{mg}$ was given once daily for 4 months and stress/rest SPECT was repeated. Metoprolol reduced the myocardial oxygen consumption, ACXCA systolic compression and thus

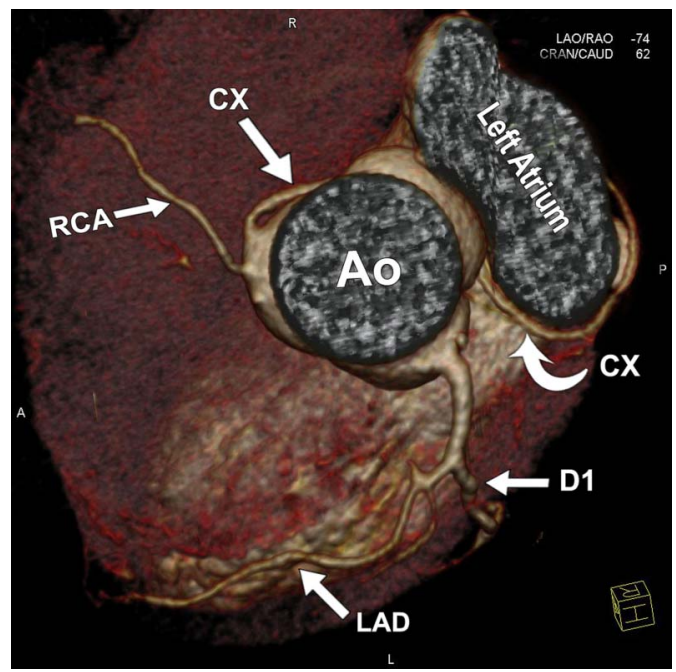

Figure 1 Volume-rendered cardiac CT images indicates extramural anomalous origin of the left circumflex (CX) coronary artery arising independently from the right sinus of Valsalva and with retroaortic course between the aortic root (Ao) and the left atrium; hypoplastic right coronary artery (RCA). Left anterior descending coronary artery (LAD) with a myocardial bridge over the first diagonal branch (D1).

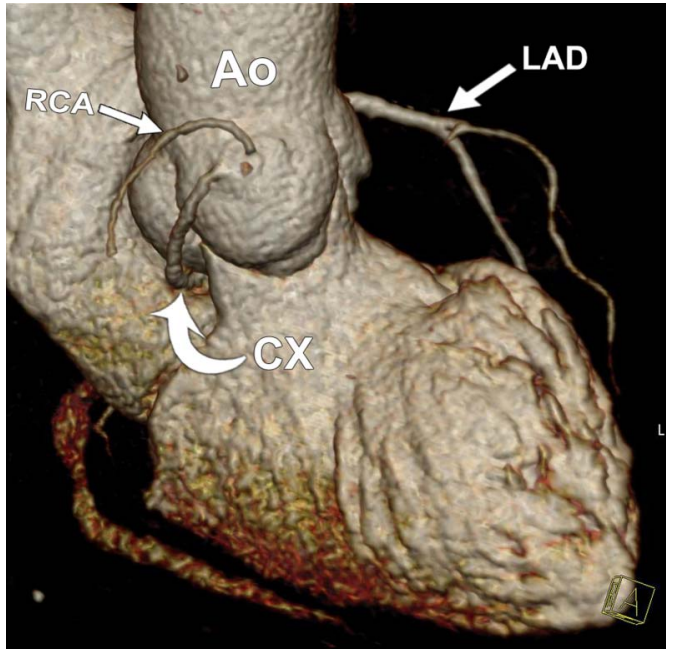

Figure 2 The right oblique volume-rendered reconstruction better delineate the independent origin of the left circumflex coronary artery (CX) from the right sinus of Valsalva and its course between the aortic root and the left atrium. Hypoplastic right coronary artery (RCA) and the left anterior descending coronary artery (LAD).

provided the release of the exercise-induced ischaemia on SPECT (figure 3). The $\beta$-blocker therapy thus protects this patient from myocardial ischaemia, myocardial infarction ${ }^{3}$ and sudden death during daily activities. Combined cardiac CT and SPECT were thus crucial techniques in determining mechanisms and proper therapy of this rare and life-threatening effort angina.

\section{Learning points}

- Myocardial ischaemia may be caused by anomalous origin of the left circumflex coronary artery with retroaortic course and hypoplastic coronary arteries.

- Cardiac CT has been established as an excellent non-invasive test to identify and classify congenital coronary anomalies.

- Stress/rest single-photon emission cardiac tomography may assess the efficacy of the medical treatment.

Contributors GPC wrote the manuscript, PS produced the CT images and revised the manuscript.

Competing interests None. 
Peak exercise at 150 Watts $-\mathrm{DP}=\mathbf{2 6 . 4 0 0}$
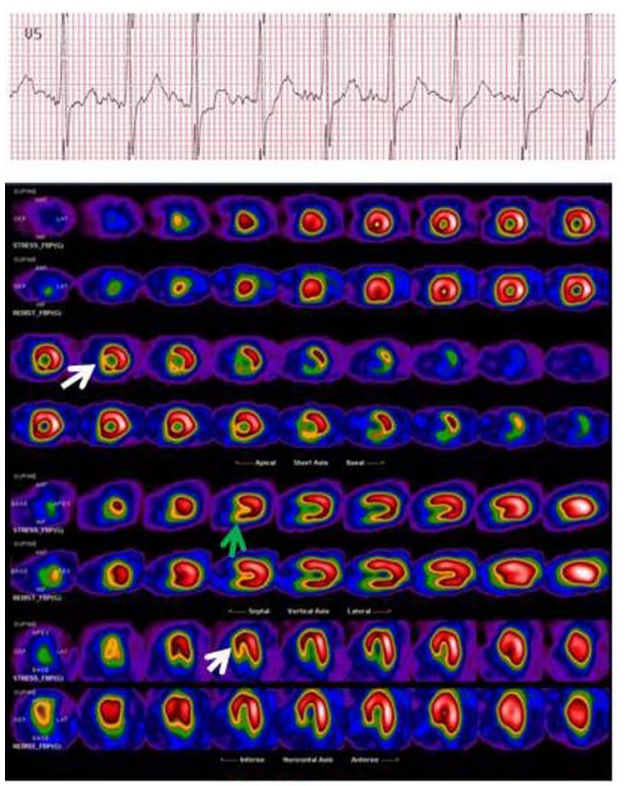

SPECT A

Peak exercise without $\beta$-blockers
Peak exercise at 150 Watts - DP $=\mathbf{2 4 . 9 0 0}$
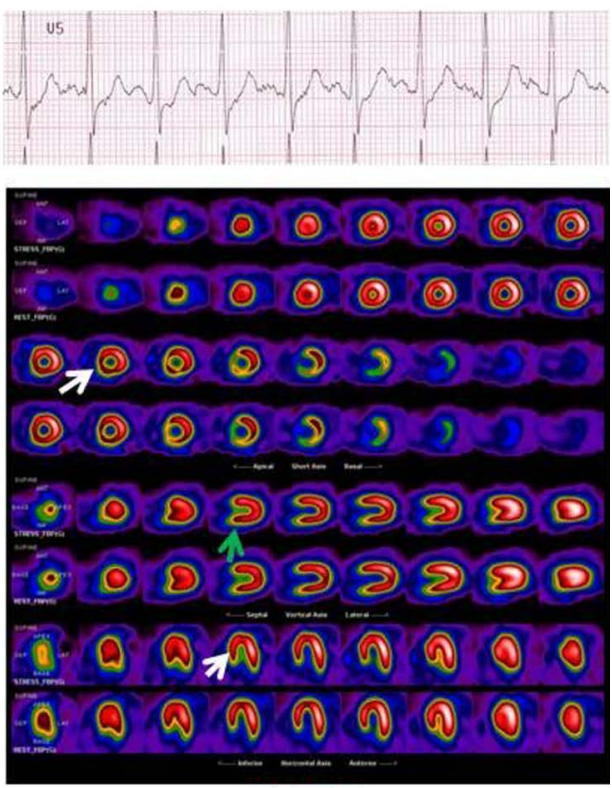

SPECT B

Peak exercise on $\beta$-blockers

Figure 3 Stress/rest thallium-201 single-photon emission cardiac tomography before (SPECT A) and after (SPECT B) therapy. Reversible perfusion defects, septal (white arrows) and inferior (green arrow). DP, double product.

\section{Patient consent Obtained}

Provenance and peer review Not commissioned; externally peer reviewed.

\section{REFERENCES}

1 Page HL Jr, Engel HJ, Campbell WB, et al. Anomalous origin of the left circumflex coronary artery. Recognition, antiographic demonstration and clinical significance. Circulation 1974;50:768-73.
2 Menke DM, Waller BF, Pless JE. Hypoplastic coronary arteries and high takeoff position of the right coronary ostium. A fatal combination of congenital coronary artery anomalies in an amateur athlete. Chest 1985;88:299-301.

3 Grasso AE, Pennell DJ. Myocardial infarction related to aberrant left circumflex artery. Int J Cardiol 2010;138:e51-2.

Copyright 2013 BMJ Publishing Group. All rights reserved. For permission to reuse any of this content visit

http://group.bmj.com/group/rights-licensing/permissions.

BMJ Case Report Fellows may re-use this article for personal use and teaching without any further permission.

Become a Fellow of BMJ Case Reports today and you can:

- Submit as many cases as you like

- Enjoy fast sympathetic peer review and rapid publication of accepted articles

- Access all the published articles

- Re-use any of the published material for personal use and teaching without further permission

For information on Institutional Fellowships contact consortiasales@bmjgroup.com

Visit casereports.bmj.com for more articles like this and to become a Fellow 